\title{
Impact of nanoparticles on neuron biology: current research trends
}

This article was published in the following Dove Press journal:

International Journal of Nanomedicine

\author{
Firdos Alam Khan \\ Dana Almohazey \\ Munthar Alomari \\ Sarah Ameen Almofty \\ Department of Stem Cell Biology, \\ Institute for Research and Medical \\ Consultations, Imam Abdulrahman Bin \\ Faisal University, Dammam, Kingdom \\ of Saudi Arabia
}

\begin{abstract}
Nanoparticles have enormous applications in textiles, cosmetics, electronics, and pharmaceuticals. But due to their exceptional physical and chemical properties, particularly antimicrobial, anticancer, antibacterial, anti-inflammatory properties, nanoparticles have many potential applications in diagnosis as well as in the treatment of various diseases. Over the past few years, nanoparticles have been extensively used to investigate their response on the neuronal cells. These nanoparticles cause stem cells to differentiate into neuronal cells and promote neuronal cell survivability and neuronal cell growth and expansion. The nanoparticles have been tested both in in vitro and in vivo models. The nanoparticles with various shapes, sizes, and chemical compositions mostly produced stimulatory effects on neuronal cells, but there are few that can cause inhibitory effects on the neuronal cells. In this review, we discuss stimulatory and inhibitory effects of various nanoparticles on the neuronal cells. The aim of this review was to summarize different effects of nanoparticles on the neuronal cells and try to understand the differential response of various nanoparticles. This review provides a bird's eye view approach on the effects of various nanoparticles on neuronal differentiation, neuronal survivability, neuronal growth, neuronal cell adhesion, and functional and behavioral recovery. Finally, this review helps the researchers to understand the different roles of nanoparticles (stimulatory and inhibitory) in neuronal cells to develop effective therapeutic and diagnostic strategies for neurodegenerative diseases.
\end{abstract}

Keywords: nanoparticles, neuron biology, neuroprotection, neurotoxicity

\section{Introduction of nanoparticles}

Nanoparticles or nanomaterials are one millionth of a millimeter, $\sim 100,000$ times smaller than the diameter of a human hair. Most nanoparticles are too small to be seen with the naked eye and even with conventional lab microscopes. Nanoparticles can be derived from both natural and synthetic sources. Over the past few years, synthetically derived nanoparticles generated tremendous interests and based on the chemical compositions, nanoparticles can be broadly classified into two major classes such as organic materials, which are liposomes, dendrimers, carbon nanotubes, emulsions, and other polymers, and inorganic materials, which include metals..$^{1-3}$ Nanoparticles can be synthesized in different sizes $(1.0-500 \mathrm{nM})$ and shapes (cones, cubes, rods, tubes, and shells). ${ }^{46}$

There are various applications of nanoparticles in biotechnology, biosensing, catalysis, magnetic fluids, separation techniques, energy storage, and environmental modification $^{7-12}$ and also in biomedical field, especially in diagnostics, and drug or gene delivery. ${ }^{13-19}$ Interestingly, nanoparticles have been extensively used as drug carrier systems for therapeutic molecules with the primary aim to improve the therapeutic effect and decrease their side effects and drug/gene delivery. ${ }^{20-23}$ One of the major attributes 
of nanoparticles is their precise targeting, biocompatibility, bioavailability, and multifunctional capabilities. ${ }^{24-26}$ In the recent past, several attempts have been made to study the effect of different classes of nanoparticles on cancer cells. ${ }^{27-38}$ In addition, interests have also been generated to study the effects of nanoparticles on neurons and there are several reports that suggest that nanoparticles promote neuronal differentiation, and neuroprotection studied in both in vitro and in vivo conditions. ${ }^{3,39-43}$ To get better therapeutic results, various types of nanoparticles have been studied in neurons, and among those, carbon-based nanoparticles are mostly reported, ${ }^{4,44-48}$ followed by gold and silver nanoparticles (AgNPs). ${ }^{49-51}$

Despite having many beneficial properties, nanoparticle also raises few health hazard and toxicity issues. To better understand the safety profile of the nanoparticles, several attempts have been made to know whether nanoparticles cause any side effects or toxic effects. It has been shown that nanomaterials possess highly activated surfaces that are capable of inducing carcinogens, mutagens, or health hazard responses. ${ }^{52-54}$ Furthermore, it has been reported that carbon nanotubes induced fibrogenesis on nanostructured substrates. ${ }^{55}$ Moreover, nanoparticles are 100 times smaller than normal red blood cells, which increase the potential for interaction, and there is evidence that nanoparticles interact with proteins, DNA, ${ }^{56}$ lung cells, and viruses. The current assumption is that nanoparticles such as silica featured as hydrophilic, hydrophobic, or even amphiphilic that can be taken up by human membranes may pose serious threats. Hence, understanding nanoparticles' interaction with living cells and other biologic systems, especially with central nervous system (CNS), is critical. Nanoparticles have potential functionality and toxic effects on human neuronal cells because they can pass through biologic membranes. ${ }^{57}$ It is known that the biologic half-life of silver in the CNS is longer than that in other organs, suggesting that there may be some significant physiologic functions, consequences, and risks to the brain because of prolonged exposure. In addition, effects of nanoparticles on the blood-brain barrier (BBB) were also evaluated, and it was found that administration of $\mathrm{Ag}, \mathrm{Cu}$, or $\mathrm{Al} / \mathrm{Al}_{2} \mathrm{O}_{3}$ nanoparticles showed disrupted $\mathrm{BBB}$ function and induced brain edema formation. ${ }^{58}$ Moreover, AgNPs induced BBB destruction and astrocyte swelling and caused neuronal degeneration. ${ }^{59}$ In the present review, we have discussed various nanoparticles and their impacts on the neuron's biology and tried to evaluate their responses (stimulatory or inhibitory), which were studied in both in vitro and in vivo models, respectively.

\section{Stimulatory effect of nanoparticles on neuronal cells}

Nanoparticles have tremendous capabilities to stimulate neuronal cells toward neuronal cell proliferation, axonal growth, neuronal cell adhesion, and neuroprotection (Figure 1). It has been demonstrated that nanoparticles can also differentiate stem cells into neuronal cells. The nanoparticles with different shapes such as nanotubes, nanofibers, nanocone, and nanoemulsion have been used to test their effects on the neuronal cells. For example, nanotubes and nanofibers promoted neuronal regeneration, activated hippocampus neurons activities, neurons growth, and neuronal protection. ${ }^{44,45,49,60-64}$ In addition, there are few reports about use of nanoscaffold,

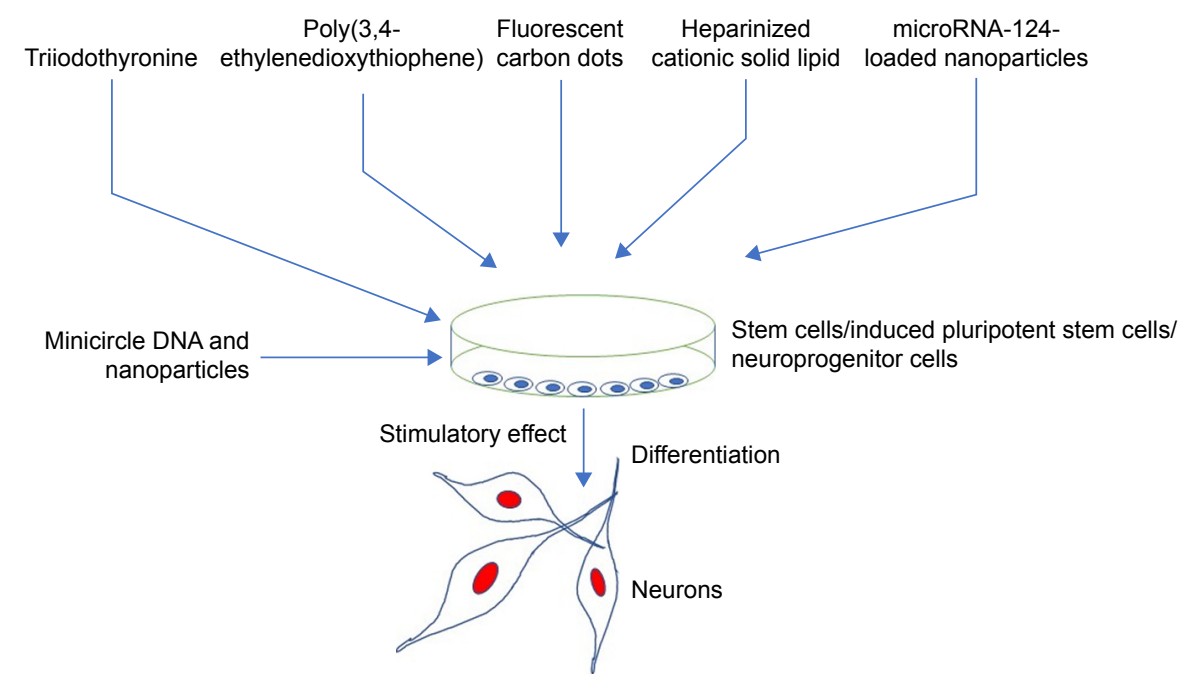

Figure I Stimulatory effect of nanoparticles on neuronal cells in an in vitro condition. 
nanocomplexes, and nanomembrane in neuron regeneration and neural tissue reconstruction. ${ }^{65-67}$ The stimulatory effects of some of the nanoparticles are diagrammatically depicted in Figure 2. Like shapes of the nanoparticles, size of the nanoparticles is also important in inducing biologic response. ${ }^{68}$ For example, nerve growth factor (NGF)-encapsulated chitosan nanoparticles with size $80-90 \mathrm{nM}$ caused differentiation of canine mesenchymal stem cells into neurons, ${ }^{69}$ whereas calcium phosphate-lipid nanoparticles with size $30 \mathrm{nM}$ caused neuronal differentiation..$^{70}$ In another report, it has been found that prodrug nanoparticles with $50 \mathrm{nM}$ size improved neuronal survival. ${ }^{71}$

Nanoparticles are either used alone or in combination or conjugation with other molecules to achieve better response on the neuronal cells. It is not easy to discuss each nanoparticle in detail, so we briefly describe the impact of nanoparticles on neurons. For example, it was reported that the use of the nanoparticle triiodothyronine along with retinoic acid caused neuronal differentiation. ${ }^{72}$ In addition, treatment of triiodothyronine along with retinoic acid also caused a significant increase in the expression of neural lineage-specific markers. Moreover, treatment of triiodothyronine also caused 10 -fold increase in the gene expression of $\beta$-III-tubulin, and five-time increase in microtubule-associated protein 2 gene expressions. ${ }^{72}$ It was reported that three-dimensional poly(3,4-ethylenedioxythiophene) doped with hyaluronic acid nanoparticles conjugated with chitosan or gelatin matrix caused neuronal cell differentiation. ${ }^{73}$ In another study, it was reported that poly(3,4-ethylenedioxythiophene) coated with microelectrodes have significantly reduced neuronal death and neuronal damage as compared to noncoated controls. ${ }^{74}$ Carbon dots (C-dots), a class of fluorescent nanoparticles with pure carbon core, have great bioanalytical potential. In addition, the application of multifunctional fluorescent C-dots caused neuronal differentiation in adult stem cells. ${ }^{75}$ In another study, it was reported that fluorescent C-dots (40-800 $\mu \mathrm{g} / \mathrm{mL}$ ) caused reduction of acidification of synaptic vesicles and increased the ambient level of the neurotransmitters. ${ }^{76}$

Interestingly, it was reported that treatment of NGF-loaded heparinized cationic solid lipid nanoparticles (HCSLNs) caused differentiation of induced pluripotent stem cells (iPSCs) into neuronal cells. ${ }^{77}$ In addition, presence of neuronspecific staining in differentiated neuronal cells confirmed that NGF-loaded HCSLNs caused neuronal cell differentiation. ${ }^{77}$ Recently, it was reported that traceable microRNA-124 -loaded nanoparticles, efficiently delivered into neural stem or progenitor cells, promoted neuronal differentiation and maturation. ${ }^{78}$ Similarly, it was reported that nanocrystalline glass-like carbon (NGLC) can induce neuronal differentiation. It was reported that NGLC caused differentiation of the dopaminergic neurons derived from the substantia nigra of the transgenic mouse embryo's brain. ${ }^{79}$ Nanoparticles caused not only the neuronal differentiation but also the formation of new cells. For example, treatment of nanoparticles caused an increased formation of daughter neuronal cells. ${ }^{80}$ In another report, it was demonstrated that polyvinylidene fluoride and poly vinylidenefluoride-co-trifluoroethylene or BaTiO3

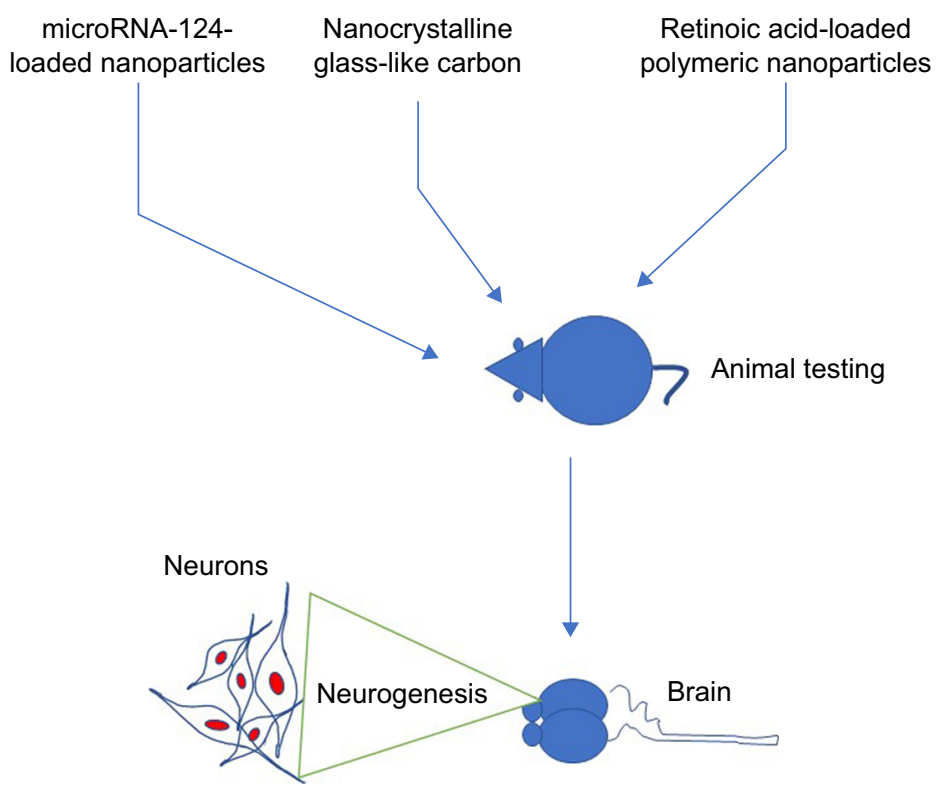

Figure 2 Stimulatory effect of nanoparticles on neuronal cell tested in animal models. 
(barium titanate) stimulated and promoted differentiation of SH-SY5Y neuroblastoma cells. ${ }^{81}$

Nanotopography is also an important factor in neuronal differentiation. For example, nanostructured zirconia surfaces produced by supersonic cluster beam deposition of zirconia nanoparticles promoted neuronal differentiation and maturation of the hippocampus neurons. ${ }^{82}$ Neurogenic niches constitute a powerful endogenous source of formation of new neurons to repair brain cells. Furthermore, it was reported that retinoic acid nanoparticles (RA-NPs) caused neurogenesis in the neural stem cells when the stem cells were exposed to blue light. ${ }^{83}$ Application of nanoparticle extracellular matrix along with conductive fiber film promoted neurite adhesion, neural alignment, and elongation of neuritis. ${ }^{84}$ The NGF-conjugated mesoporous silica nanoparticle was reported to promote neuron proliferation and neurite growth in pheochromocytoma (PC12) cell line. ${ }^{85}$ In the same study, it was reported that use of NGF-conjugated mesoporous silica nanoparticle significantly promoted differentiation of neuron-like PC12 cells and growth of neurites compared to NGF alone. ${ }^{85}$ This report suggests that use of nanoparticles along with NGFs improves neuronal cell differentiation many fold. Nanopatterned SU-8 surface using nanosphere lithography was reported to enhance neuronal cell growth. ${ }^{86}$ Moreover, nanotopography also promoted neuronal differentiation of human iPSCs. ${ }^{87}$

The treatment of nanoparticles not only induces neuronal differentiation but also improves functional or behavioral recovery in animal models (Figure 2). For example, Zhang et al reported that treatment of small interfering RNA along with retinoic acid resulted in attenuation of neuronal loss and restoration of memory deficiencies in mice. Moreover, an intracerebroventricular injection of microRNA-124-loaded nanoparticles into a mouse model of Parkinson's disease caused an increased formation of new neurons in the olfactory bulb. ${ }^{88}$ In the same study, it was found that microRNA-124loaded nanoparticles enhanced migration of new neurons into the lesioned striatum of mice and caused improvement of motor function. ${ }^{88}$ In another study, it was reported that an administration of triiodothyronine in a rat model of ischemic stroke was reported to cause a $34 \%$ decrease in tissue infarction and a $59 \%$ decrease in brain edema. ${ }^{89}$

In another report, it was demonstrated that RA-NPs enhanced vascular regulation of neural stem cell and promoted neuronal cell survival and neuronal cell differentiation after ischemia effect. ${ }^{90}$ In addition, it was found that treatment of RA-NP protected endothelial cells from ischemic death and stimulated the release of prosurvival, proliferation-stimulating factors for neural stem cells. ${ }^{90} \mathrm{It}$ would be interesting to investigate the effect of triiodothyronine or microRNA-124-loaded nanoparticles in other animal models to check whether it can also enhance functional and behavioral recovery. In addition to use of nanoparticles for the neuronal differentiation, nanoparticles have also been used to deliver drugs in the neuronal cells. For example, it was reported that the minicircle DNA and nanoparticles were used to deliver a neurotherapeutic gene into neural stem cells. ${ }^{80}$ In the same study, it was demonstrated that minicircles DNA along with magnetofection technology caused the overexpression of brain-derived neurotrophic factor gene in neural stem cells. ${ }^{80}$

We have summarized other nanoparticles based on their stimulatory actions in tabular form. For example, in Table 1, we have listed the nanoparticles with stimulatory effects on neurons tested under both in vitro culture and in vivo conditions. The stimulatory effects of nanoparticles caused an increased neuronal cell differentiation and promoted nerve regeneration, hippocampal neuron activity, cell viability, neuronal growth and cerebral neuronal induction, and gene expression in nigral dopaminergic neurons. They also promoted neuronal growth, axonal guidance, Schwann cells' guidance, neural tissue reconstruction, neuronal-glial interaction, neurogenesis, and neuroprotection. These nanoparticles with different shapes, sizes, and chemical compositions improved nerve regeneration, neuronal recovery, neuronal signaling, neuroprotection, and neurogenesis in various animal models. These nanoparticles were also able to improve functional and behavioral recovery of the motor functions in the animal models of Parkinson's disease and spinal cord injury.

\section{Inhibitory effect of nanoparticles on neuronal cells}

Despite having therapeutic potentials, nanoparticles pose safety concerns. There are few nanoparticles, which are also reported to have inhibitory effects on the neuronal cells. These nanoparticles caused opposite and damaging action on the neuronal differentiation. The inhibitory effect on the neuronal differentiation is diagrammatically depicted in Figure 3. It was reported that cerium oxide nanoparticles displayed antioxidant properties in both in vitro and in vivo conditions and caused an inhibitory effect on the neural stem cells by inhibiting the neuronal cell differentiation. ${ }^{91}$ In addition, detailed computational analyses showed that cerium oxide altered pathways and networks relevant to neuronal development and 
Table I List of various nanoparticles with stimulatory effects on neurons

\begin{tabular}{|c|c|}
\hline Name of nanoparticles & Activities measured \\
\hline Nanofibrous scaffold & Promoted nerve regeneration ${ }^{65}$ \\
\hline Carbon nanotube & $\begin{array}{l}\text { Promoted hippocampal neurons' } \\
\text { activity }{ }^{97}\end{array}$ \\
\hline Nanofibers & Promoted nerve regeneration ${ }^{98}$ \\
\hline Gold nanotubes & Promoted nerve regeneration ${ }^{49}$ \\
\hline Silica & Increased cell viability99 \\
\hline Gold nanocone & Increased neuronal growth ${ }^{100}$ \\
\hline BNDF-PS80-PBCA & Promoted neuronal differentiation ${ }^{101}$ \\
\hline Gatifloxacine & Promoted cerebral neuronal induction ${ }^{102}$ \\
\hline NTS-polyplex nanoparticle & $\begin{array}{l}\text { Promoted gene expression in nigral } \\
\text { dopaminergic neurons }{ }^{103}\end{array}$ \\
\hline Core-shell nanoparticles & Promoted nerve regeneration ${ }^{104}$ \\
\hline $\begin{array}{l}\text { Poly(lactide-co-glycolide) } \\
\text { nanoparticles }\end{array}$ & Promoted nerve regeneration 105 \\
\hline Electrospun fiber scaffolds & Promoted neuronal growth ${ }^{60}$ \\
\hline Magnetic nanoparticles & Reversed Parkinson's syndrome ${ }^{106}$ \\
\hline Zero valent zinc nanoparticles & Promoted neuronal proliferation 107 \\
\hline $\begin{array}{l}\text { Curcumin-docosahexaenoic } \\
\text { acid-loaded carriers }\end{array}$ & Promoted neuronal survival ${ }^{42}$ \\
\hline $\begin{array}{l}\text { Graphene and carbon } \\
\text { nanotube }\end{array}$ & Promoted neuronal biocompatibility ${ }^{108}$ \\
\hline Active microcarriers & Promoted neuronal differentiation 109 \\
\hline $\begin{array}{l}\text { Gelatin/nanoceria } \\
\text { nanocomposite fibers }\end{array}$ & Promoted neuronal regeneration ${ }^{61}$ \\
\hline Poly lactic acid scaffolds & Promoted neuronal growth ${ }^{66}$ \\
\hline Micellar nanocomplexes & Promoted axonal guidance ${ }^{110}$ \\
\hline Nanoporous surface & Promoted neuronal differentiation"II \\
\hline $\begin{array}{l}\text { Fluorescent polymeric } \\
\text { nanovehicles }\end{array}$ & Promoted neuronal modulation 112 \\
\hline $\begin{array}{l}\text { Electrospun poly(methyl } \\
\text { methacrylate) nanofibers }\end{array}$ & Promoted Schwann cells guidance ${ }^{1 / 3}$ \\
\hline Nanofiber membrane & Promoted neural tissue reconstruction ${ }^{1 / 4}$ \\
\hline Nanowires & Promoted nerve regeneration ${ }^{115}$ \\
\hline Titanium dioxide nanoparticle & Promoted neuronal-glial interaction ${ }^{116}$ \\
\hline $\begin{array}{l}\text { Microgroove electroactive } \\
\text { composite film }\end{array}$ & Promoted neuronal guidance ${ }^{117}$ \\
\hline $\begin{array}{l}\text { Tenascin- } \mathrm{C} \text { mimetic peptide } \\
\text { amphiphile nanofiber }\end{array}$ & Promoted neuronal growth ${ }^{63}$ \\
\hline Chitin and carbon nanotube & Promoted neuronal growth ${ }^{46}$ \\
\hline Solid lipid nanoparticles & Promoted neuronal protection ${ }^{118}$ \\
\hline Electrospun silica nanofiber & Promoted neuronal growth ${ }^{64}$ \\
\hline Peptide nanofibers & Promoted neurogenesis 119 \\
\hline $\begin{array}{l}\text { Galantamine/chitosan } \\
\text { complex nanoparticles }\end{array}$ & Promoted neuronal protection ${ }^{120}$ \\
\hline Hybrid microfluidic system & Promoted neuronal differentiation ${ }^{|2|}$ \\
\hline Multiwalled carbon nanotubes & Promoted neuroprotection ${ }^{45}$ \\
\hline Carbon nanomaterials & Promoted neuronal adhesion ${ }^{44}$ \\
\hline Cationic nanoemulsion & Prevented neuroinflammation ${ }^{122}$ \\
\hline Nanofiber hydrogels & Promoted nerve regeneration ${ }^{43}$ \\
\hline
\end{tabular}

inhibited neuronal differentiation. ${ }^{91}$ It was found that cerium oxide caused a decrease in neuron-specific $\beta 3$-tubulin expression, a marker of neuronal differentiation, and glial fibrillary acidic protein, a neuroglial marker. ${ }^{91}$ In contrast to this report, cerium oxide nanoparticles promoted neurogenesis and abrogated hypoxia-induced memory impairment through AMP-activated protein kinase-protein kinase C-cAMPresponse element binding protein (CREB)-binding protein signaling cascade in the rat. ${ }^{92}$ In another study, nanoparticle exposure did not impair cell viability and neuroinflammation in primary hippocampal cultures, but significantly decreased the neuronal differentiation markers in human SH-SY5Y cells. ${ }^{93}$ We do not know the reason of the contradicting responses of cerium oxide on neuronal cells, and the possibility of using different concentrations or different sizes of cerium oxide could be one of the reasons. Nevertheless, detailed studies must be undertaken with different sizes of cerium oxide to understand cerium oxide's role.

Polyamidoamine (PAMAM) dendrimer has many biologic applications that include delivering gene or drug molecules to the cells. Despite having potential therapeutic and diagnostic application, PAMAM also caused some cytotoxic effects. It was reported that PAMAM dendrimer exposure caused an adverse effect on neuronal cell differentiation and adverse effect associated with oxidative stress and DNA damage. ${ }^{94}$ In addition, PAMAM dendrimer was reported to inhibit neutrosphere growth. In the same study, it was reported that PAMAM reduced number of microtubule-associated protein 2-positive cells after 10 days of differentiation. ${ }^{94}$ In another report, AgNPs induced inflammatory response in neuronal cells. ${ }^{9}$ It was reported that AgNPs entered the nuclei of mouse neuronal cells and induced progression of neurodegenerative disorder. ${ }^{9}$ It was reported that silver nitrate treatment increased cellular superoxide dismutase activity and decreased mitochondrial membrane potential, leading to neuronal death. ${ }^{11}$ In addition, even a low concentration of AgNPs interrupted early neuronal processes and facilitated neuron apoptosis by increased cellular oxidative stress and mitochondrial disruption. ${ }^{11}$ In another study, it was reported that silica-indocyanine green/poly ( $\varepsilon$-caprolactone) nanoparticles caused no neuronal differentiation because of mitochondrial damage. ${ }^{95}$ We have summarized other nanoparticles that are having inhibitory and cytotoxic effects on neurons, in tabular forms. For example, inhibitory and cytotoxic effects on neurons studied in in vitro models are shown in Table 2, whereas inhibitory and cytotoxic effects studied in animal models are shown in Table 3.

\section{Risks and challenges of nanoparticles on neuronal cells}

Despite having so many beneficial properties, the nanoparticles also cause some health concerns because of their small size and chemical compositions. Researchers were 


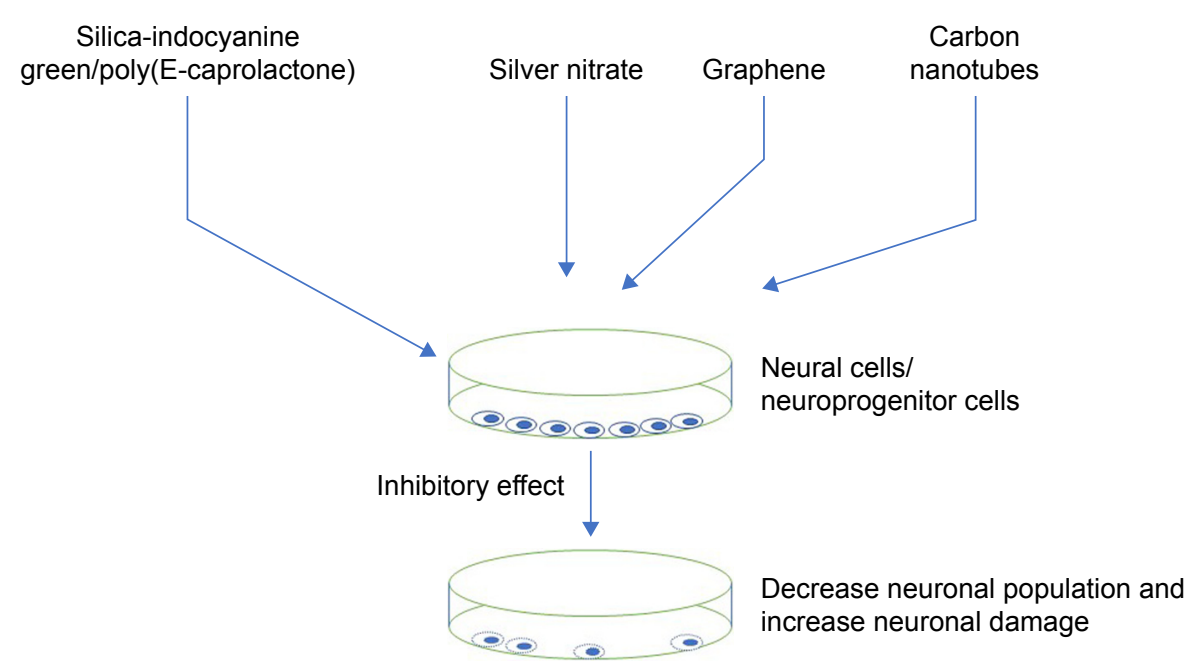

Figure 3 Inhibitory effect of nanoparticles on neuronal cells tested in an in vitro condition.

interested to find out whether nanoparticles do exert some negative effects on the neuron biology. Recently, it has been reported that the use of low concentration of AgNPs caused neuronal damage ${ }^{96}$ and also treatment of silica nanoparticles impaired the mitochondrial function during neuronal differentiation..$^{96}$ In another study, it was reported that PAMAM dendrimers with various surface functional groups caused cytotoxic effects on neuronal differentiation in human neural progenitor cells. ${ }^{94}$ These nanoparticles upon testing under in vitro conditions promoted neuronal damage and induced neurodegeneration, neuronal cytotoxicity, and neurotoxicity. Like in vitro models, nanoparticles have also been tested in animal models, which induced neuronal damage, neuronal degeneration, neuronal damage, neuronal toxicity, cell death, and impaired BBB. We have listed other nanoparticles that are also reported to cause toxic effects on neuronal cells, in Tables 2 and 3.

\section{Summary}

Nanoparticles have many potential applications, which include the promotion and activation of neuronal cell differentiation as reported in both in vitro and in vivo models.

Table 2 List of various nanoparticles with neurotoxic effects on neurons tested in in vitro conditions

\begin{tabular}{ll}
\hline Name of nanoparticles & Activities measured \\
\hline Silver nanoparticles & Promoted neuronal damage ${ }^{116}$ \\
Trimethyltin & Induced neuronal degeneration ${ }^{125}$ \\
Copper oxide nanoparticles & Induced neurodegeneration \\
Magnetite nanoparticles & Induced neuronal cytotoxicity \\
Nanocrystals containing & Induced neurotoxicity \\
phospholipid micelles & \\
\hline
\end{tabular}

Nanoparticles can also reverse the neurologic impairments in the animal models of neurologic disorders such as brain ischemia and Parkinson's and Alzheimer's diseases. Research has shown that many nanoparticles promoted neuronal differentiation and enhanced neuronal survival and neuronal growth and maturation. But there are few nanoparticles that do not promote neuronal differentiation and cause neuronal damage or neurotoxicity. To achieve better response on the neuronal cells, researchers have used different sizes and shapes of nanoparticles. Sometimes one nanoparticle is conjugated with another nanoparticle or biomolecules to enhance the effects. Nanoparticles not only induce neuronal differentiation but also induce functional or behavioral recovery in animal models. The size of nanoparticles is also an important factor for their actions on the neurons. The researchers must know the size of nanoparticles before testing them for anticipated response. Most of the current data are based on morphologic, anatomical, and behavioral parameters, and still we do not know molecular mechanisms behind nanoparticle action on neurons. It would be interesting to study the molecular mechanism of the nanoparticle action on neurons.

Table 3 List of nanoparticles with inhibitory effects on neurons, which are tested in animal models

\begin{tabular}{ll}
\hline Name of nanoparticles & Activities measured \\
\hline Trimethyltin & Induced neuronal degeneration ${ }^{125}$ \\
Cadmium telluride & Induced neuronal damage and \\
quantum dots & function \\
Carbon nanotubes & Induced neuronal toxicity \\
Nanofiber & Impaired blood-brain barrier \\
Graphene & Induced neuronal damage \\
Airborne nanoparticle & Induced cell death \\
\hline
\end{tabular}




\section{Future direction}

The nanoparticles hold a great promise for both diagnostic and therapeutic applications for various neurodegenerative diseases. They are also viable candidates to deliver neuroprotective molecules in the body for both diagnostic and therapeutic applications. The success of nanoparticles in neural areas depends on the consistent data generation, which depicts less variability in both in vitro and in vivo models. The cytotoxic effects of nanoparticles also need to be properly studied with proper dosages and correct treatment modalities to minimize the risk. Nanoparticles with stimulatory or inhibitory actions can be first studied through in vitro models, then through in vivo models. The results of both in vitro and in vivo studies must be compared and analyzed before calling nanoparticle stimulators or inhibitors. This strategy would help the researchers to identify and select potential nanoparticles for therapeutic and diagnostic purposes. Finally, nanoparticles with higher efficacy and ability to repair the damaged neurons with the least side effects in both in vitro and in vivo models hold great promise for the patients suffering from various neurodegenerative diseases.

\section{Availability of data and material}

The data analyzed are available from the corresponding author upon a request.

\section{Acknowledgments}

The authors are thankful to the entire management of the Institute for Research and Medical Consultations (IMRC), Imam Abdulrahman Bin Faisal University, Dammam, Kingdom of Saudi Arabia, for their support and encouragement.

\section{Disclosure}

The authors report no conflicts of interest in this work.

\section{References}

1. Kuang YH, Chen X, Su J, et al. RNA interference targeting the CD147 induces apoptosis of multi-drug resistant cancer cells related to XIAP depletion. Cancer Lett. 2009;276:189-195.

2. Chowdhury EH, Rosli R, Karim ME. Systemic delivery of nanoformulations of anti-cancer drugs with therapeutic potency in animal models of cancer. Curr Cancer Ther Rev. 2016;12:1-17.

3. Chowdhury EH. Nanotherapeutics: From Laboratory to Clinic. Boca Raton, FL: CRC Press; 2016.

4. Murphy CJ, Jana NR. Controlling the aspect ratio of inorganic nanorods and nanowires. Adv Mater. 2002;(14):80.

5. Sun Y, Xia Y. Shape-controlled synthesis of gold and silver nanoparticles. Science. 2002;(298):2176.

6. Balasubramanian B, Kraemer KL, Reding NA, Skomski R, Ducharme S, Sellmyer DJ. Synthesis of monodisperse $\mathrm{TiO}(2)$-paraffin core shell nanoparticles for improved dielectric properties. ACS Nano. 2010;4(4): 1893-1900.
7. Cai J, Miao Y, Yu B, Ma P, Li L, Fan H. Large-scale, facile transfer of oleic acid-stabilized iron oxide nanoparticles to the aqueous phase for biological applications. Langmuir. 2017;33:1662-1669.

8. Schrittwieser S, Pelaz B, Parak WJ, et al. Homogeneous biosensing based on magnetic particle labels. Sensors. 2016;16:828.

9. Lin F, Doong R. Catalytic nanoreactors of $\mathrm{Au} @ \mathrm{Fe}_{3} \mathrm{O}_{4}$ yolk-shell nanostructures with various Au sizes for efficient nitroarene reduction. J Phys Chem C. 2017;121:7844-7853.

10. Han L, Zhang Y, Lu X, Wang K, Wang Z, Zhang H. Polydopamine nanoparticles modulating stimuli-responsive PNIPAM hydrogels with cell/tissue adhesiveness. ACS Appl Mater Interfaces. 2016;8: 29088-29100.

11. Guo X, Zhang G, Chen L, Khan AA, Gu B, Li B. Newborn neurons are damaged in vitro by a low concentration of silver nanoparticles through the inflammatory oxidative stress pathway. DNA Cell Biol. 2017;36(12):1062-1070.

12. Zhou X, Yang A, Huang Z, Yin G, Pu X, Jin J. Enhancement of neurite adhesion, alignment and elongation on conductive polypyrrolepoly(lactide acid) fibers with cell-derived extracellular matrix. Colloids Surf B Biointerfaces. 2017;149:217-225.

13. Zhao YZ, Jin RR, Yang W, et al. Using gelatin nanoparticle mediated intranasal delivery of neuropeptide substance $P$ to enhance neurorecovery in hemiparkinsonian rats. PLoS One. 2016;11(2):e0148848.

14. Kuang Y, Zhang K, Cao Y, et al. Hydrophobic IR-780 dye encapsulated in cRGD-conjugated solid lipid nanoparticles for NIR imagingguided photothermal therapy. ACS Appl Mater Interfaces. 2017;9: 12217-12226.

15. Lin HC, Huang CL, Huang YJ, Hsiao IL, Yang CW, Chuang CY. Transcriptomic gene-network analysis of exposure to silver nanoparticle reveals potentially neurodegenerative progression in mouse brain neural cells. Toxicol In Vitro. 2016;34:289-299.

16. Wang S, Zhao X, Wang S, Qian J, He S. Biologically inspired polydopamine capped gold nanorods for drug delivery and light-mediated cancer therapy. ACS Appl Mater Interfaces. 2016;8:24368-24384.

17. Chen J, Wang Q, Zhou J, et al. Porphyra polysaccharide-derived carbon dots for non-viral co-delivery of different gene combinations and neuronal differentiation of ectodermal mesenchymal stem cells. Nanoscale. 2017;9(30):10820-10831.

18. Saha A, Mohanta SC, Deka K, Deb P, Devi PS. Surface-engineered multifunctional Eu: $\mathrm{Gd}_{2} \mathrm{O}_{3}$ nanoplates for targeted and $\mathrm{pH}$-responsive drug delivery and imaging applications. ACS Appl Mater Interfaces. 2017;9:4126-4141.

19. Kemp JA, Shim MS, Heo CY, Kwon YJ. "Combo" nanomedicine: co-delivery of multi-modal therapeutics for efficient, targeted, and safe cancer therapy. Adv Drug Deliv Rev. 2016;98:3-18.

20. He K, Ma Y, Yang B, Liang C, Chen X, Cai C. The efficacy assessments of alkylating drugs induced by nano- $\mathrm{Fe}_{3} \mathrm{O}_{4} / \mathrm{CA}$ for curing breast and hepatic cancer. Spectrochim Acta A. 2017;173:82-86.

21. Shahabadi N, Akbari A, Jamshidbeigi M, Falsafi M. Functionalization of $\mathrm{Fe}_{3} \mathrm{O}_{4} @ \mathrm{SiO}_{2}$ magnetic nanoparticles with nicotinamide and in vitro DNA interaction. J Mol Liq. 2016;224:227-233.

22. Xing R, Liu G, Zhu J, Hou Y, Chen X. Functional magnetic nanoparticles for non-viral gene delivery and MR imaging. Pharm Res. 2014; 31:1377-1389.

23. Saei AA, Barzegari A, Majd MH, Asgari D, Omidi Y. $\mathrm{Fe}_{3} \mathrm{O}_{4}$ nanoparticles engineered for plasmid DNA delivery to Escherichia coli. J Nanopart Res. 2014;16:1-11.

24. Aftab S, Shah A, Nadhman A, et al. Nanomedicine: an effective tool in cancer therapy. Int J Pharm. 2018;540(1-2):132-149.

25. Afrimzon E, Deutsch A, Shafran Y, et al. Intracellular esterase activity in living cells may distinguish between metastatic and tumor-free lymph nodes. Clin Exp Metastasis. 2008;25:213-224.

26. Zhao J, Castranova V. Toxicology of nanomaterials used in nanomedicine. J Toxicol Environ Health B Crit Rev. 2011;14(8):593-632.

27. Gottlieb E, Armour SM, Harris MH, Thompson CB. Mitochondrial membrane potential regulates matrix configuration and cytochrome $\mathrm{C}$ release during apoptosis. Cell Death Differ. 2003;10(6):709-717. 
28. Wood A, Schneider J, Shilatifard A. Cross-talking histones: implications for the regulation of gene expression and DNA repair. Biochem Cell Biol. 2005;83(4):460-467.

29. Smalley KS, Herlyn M. Towards the targeted therapy of melanoma. Mini Rev Med Chem. 2006;6(4):387-393.

30. Unfried K, Albrecht C, Klotz LO, von Mikecz A, Grether-Beck S, Schins RPF. Cellular responses to nanoparticles: target structures and mechanisms. Nanotoxicology. 2007;1(1):52-71.

31. Hanley C, Layne J, Punnoose A, et al. Preferential killing of cancer cells and activated human $\mathrm{T}$ cells using $\mathrm{ZnO}$ nanoparticles. Nanotech. 2008;19(29):295103.

32. Turcotte S, Chan DA, Sutphin PD, Hay MP, Denny WA, Giaccia AJ. A molecule targeting VHL-deficient renal cell carcinoma that induces autophagy. Cancer Cell. 2008;14(1):90-102.

33. Wang H, Wick RL, Xing B. Toxicity of nanoparticulate and bulk $\mathrm{ZnO}$, $\mathrm{A} 12 \mathrm{O} 3$ and $\mathrm{TiO} 2$ to the nematode Caenorhabditis elegans. Environ Pollut. 2009;157(4):1171-1177.

34. Rasmussen JW, Martinez E, Louka P, Wingett DG. Zinc oxide nanoparticles for selective destruction of tumor cells and potential for drug delivery applications. Expert Opin Drug Del. 2010;7(9):1063-1077.

35. Mathew R, White E. Autophagy in tumorigenesis and energy metabolism: friend by day, foe by night. Curr Opin Genet Dev. 2011;21(1): 113-119.

36. Wang X, Wang W, Li L, Perry G, Lee HG, Zhu X. Oxidative stress and mitochondrial dysfunction in Alzheimer's disease. Biochim Biophys Acta. 2014;1842(8):1240-1247.

37. Yaffee P, Osipov A, Tan C, Tuli R, Hendifar A. Review of systemic therapies for locally advanced and metastatic rectal cancer. $J$ Gastrointest Oncol. 2015;6:185-200.

38. Pati R, Das I, Mehta RK, Sahu R, Sonawane A. Zinc-oxide nanoparticles exhibit genotoxic, clastogenic, cytotoxic and actin depolymerization effects by inducing oxidative stress responses in macrophages and adult mice. Toxicol Sci. 2016;150(2):454-472.

39. Bhang SH, Han J, Jang HK, et al. pH-triggered release of manganese from $\mathrm{MnAu}$ nanoparticles that enables cellular neuronal differentiation without cellular toxicity. Biomaterials. 2015;55:33-43.

40. Wang K, He X, Linthicum W, et al. Carbon nanotubes induced fibrogenesis on nanostructured substrates. Environ Sci Nano. 2017;4(3): 689-699.

41. Dante S, Petrelli A, Petrini EM, et al. Selective targeting of neurons with inorganic nanoparticles: revealing the crucial role of nanoparticle surface charge. ACS Nano. 2017;11(7):6630-6640.

42. Guerzoni LP, Nicolas V, Angelova A. In vitro modulation of TrkB receptor signaling upon sequential delivery of curcumin-DHA loaded carriers towards promoting neuronal survival. Pharm Res. 2017;34(2): 492-505.

43. Sun B, Taing A, Liu H, et al. Nerve growth factor-conjugated mesoporous silica nanoparticles promote neuron-like PC12 cell proliferation and neurite growth. J Nanosci Nanotechnol. 2016;16(3):2390-2393.

44. Franca E, Jao PF, Fang SP, et al. Scale of carbon nanomaterials affects neural outgrowth and adhesion. IEEE Trans Nanobioscience. 2016; 15(1):11-18.

45. Ding S, Bao Y, Lin Y, et al. Neuroprotective effect of functionalized multi-walled carbon nanotubes on spinal cord injury in rats. Int J Clin Exp Pathol. 2015;8(12):15769-15777.

46. Singh N, Chen J, Koziol KK, et al. Chitin and carbon nanotube composites as biocompatible scaffolds for neuron growth. Nanoscale. 2016;8(15):8288-8299.

47. Singh A, Kim W, Kim Y, et al. Multifunctional photonics nanoparticles for crossing the blood-brain barrier and effecting optically trackable brain theranostics. Adv Funct Mater. 2016;26(39):7057-7066.

48. Gholamine B, Karimi I, Salimi A, Mazdarani P, Becker LA. Neurobehavioral toxicity of carbon nanotubes in mice. Toxicol Ind Health. 2017; 33(4):340-350.

49. Wei M, Li S, Yang Z, Zheng W, Le W. Gold nanoparticles enhance the differentiation of embryonic stem cells into dopaminergic neurons via mTOR/p70S6K pathway. Nanomedicine (Lond). 2017;12(11): 1305-1317.
50. Hsiao IL, Chang CC, Wu CY, et al. Indirect effects of TiO2 nanoparticle on neuron-glial cell interactions. Chem Biol Interact. 2016;254: $34-44$.

51. Lin R, Li Y, MacDonald T, et al. Improving sensitivity and specificity of capturing and detecting targeted cancer cells with anti-biofouling polymer coated magnetic iron oxide nanoparticles. Colloids Surf B Biointerfaces. 2017;150:261-270.

52. Seemayer NH, Hadnagy W, Tomingas T. Evaluation of health risks by airborne particulates from in vitro cyto- and genotoxicity testing on human and rodent tissue culture cells: a longitudinal study from 1975 until now. J Aerosol Sci. 1990;21(Suppl 1):S501-S504.

53. Seaton A, Tran L, Aitken R, Donaldson K. Nanoparticles, human health hazard and regulation. J R Soc Interface. 2010;7:S119-S129.

54. Wang S, Guan $\mathrm{S}, \mathrm{Xu}$ J, et al. Neural stem cell proliferation and differentiation in the conductive PEDOT-HA/Cs/Gel scaffold for neural tissue engineering. Biomater Sci. 2017;5(10):2024-2034.

55. Wang K, Huang Q, Qiu F, Sui M. Non-viral delivery systems for the application in p53 cancer gene therapy. Curr Med Chem. 2015;22(35): 4118-4136.

56. Sever M, Turkyilmaz M, Sevinc C, et al. Regenerative effects of peptide nanofibers in an experimental model of Parkinson's disease. Acta Biomater. 2016;46:79-90.

57. Brooking J, Davis SS, Illum L. Transport of nanoparticles across the rat nasal mucosa. J Drug Targeting. 2001;9:267-279.

58. Sharma HS, Hussain S, Schlager J, Ali SF, Sharma A. Influence of nanoparticles on blood-brain barrier permeability and brain edema formation in rats. Acta Neurochir Suppl. 2010;106: 359-364.

59. Tang J, Xiong L, Wang S, et al. Distribution, translocation and accumulation of silver nanoparticles in rats. J Nanosci Nanotechnol. 2009; 9:4924-4932.

60. Jakobsson A, Ottosson M, Zalis MC, O’Carroll D, Johansson UE, Johansson F. Three-dimensional functional human neuronal networks in uncompressed low-density electrospunfiber scaffolds. Nanomedicine. 2017;13(4):1563-1573.

61. Marino A, Tonda-Turo C, De Pasquale D, et al. mGelatin/nanoceria nanocomposite fibers as antioxidant scaffolds for neuronal regeneration. Biochim Biophys Acta. 2017;1861(2):386-395.

62. Xia H, Sun X, Liu D, Zhou Y, Zhong D. Oriented growth of rat Schwann cells on aligned electrospun poly(methyl methacrylate) nanofibers. J Neurol Sci. 2016;369:88-95.

63. Berns EJ, Álvarez Z, Goldberger JE, et al. A tenascin-C mimetic peptide amphiphile nanofiber gel promotes neurite outgrowth and cell migration of neurosphere-derived cells. Acta Biomater. 2016;37:50-58.

64. Feng ZV, Chen WS, Keratithamkul K, et al. Degradation of the electrospun silica nanofiber in a biological medium for primary hippocampal neuron-effect of surface modification. Int J Nanomedicine. 2016;11:729-741

65. Hackelberg S, Tuck SJ, He L, et al. Nanofibrous scaffolds for the guidance of stem cell-derived neurons for auditory nerve regeneration. PLoS One. 2017;12(7):e0180427.

66. Haddad T, Noel S, Liberelle B, El Ayoubi R, Ajji A, De Crescenzo G. Fabrication and surface modification of poly lactic acid (PLA) scaffolds with epidermal growth factor for neural tissue engineering. Biomatter. 2016;6(1):e1231276.

67. Huang D, Lin C, Wen X, Gu S, Zhao P. A potential nanofiber membrane device for filling surgical residual cavity to prevent glioma recurrence and improve local neural tissue reconstruction. PLoS One. 2016;11(8):e0161435

68. Strużyńska L, Skalska J. Mechanisms underlying neurotoxicity of silver nanoparticles. Adv Exp Med Biol. 2018;1048:227-250.

69. Mili B, Das K, Kumar A, et al. Preparation of NGF encapsulated chitosan nanoparticles and its evaluation on neuronal differentiation potentiality of canine mesenchymal stem cells. J Mater Sci Mater Med. 2017;29(1):4.

70. Chen L, Watson C, Morsch M, et al. Improving the delivery of SOD1 antisense oligonucleotides to motor neurons using calcium phosphatelipid nanoparticles. Front Neurosci. 2017;11:476. 
71. Markoutsa E, Xu P. Redox potential-sensitive N-acetyl cysteineprodrug nanoparticles inhibit the activation of microglia and improve neuronal survival. Mol Pharm. 2017;14(5):1591-1600.

72. Satish A, Korrapati PS. Tailored release of triiodothyronine and retinoic acid from a spatio-temporally fabricated nanofiber composite instigating neuronal differentiation. Nanoscale. 2017;9(38):14565-14580.

73. Wong A, Liu Q, Griffin S, Nicholls A, Regalbuto JR. Synthesis of ultrasmall, homogeneously alloyed, bimetallic nanoparticles on silica supports. Science. 2017;358(6369):1427-1430.

74. Kolarcik CL, Catt K, Rost E, et al. Evaluation of poly(3,4-ethylenedioxythiophene)/carbon nanotube neural electrode coatings for stimulation in the dorsal root ganglion. J Neural Eng. 2015;12(1): 016008 .

75. Chen D, Yang D, Dougherty C, et al. In vivo targeting and positron emission tomography imaging of tumor with intrinsically radioactive metalorganic frameworks nanomaterials. ACS Nano. 2017;11:4315-4327.

76. Borisova T, Nazarova A, Dekaliuk M, et al. Neuromodulatory properties of fluorescent carbon dots: effect on exocytotic release, uptake and ambient level of glutamate and GABA in brain nerve terminals. Int $J$ Biochem Cell Biol. 2015;59:203-215.

77. Kuo YC, Chen CW. Neuroregeneration of induced pluripotent stem cells in polyacrylamide-chitosan inverted colloidal crystal scaffolds with poly(lactide-co-glycolide) nanoparticles and transactivator of transcription von Hippel-Lindau peptide. Tissue Eng Part A. 2017; 23(7-8):263-274.

78. Saraiva C, Ferreira L, Bernardino L. Traceable microRNA-124 loaded nanoparticles as a new promising therapeutic tool for Parkinson's disease. Neurogenesis (Austin). 2016;3(1):e1256855.

79. Rodriguez-Losada N, Romero P, Estivill-Torrús G, Guzmán de Villoria R, Aguirre JA. Cell survival and differentiation with nanocrystalline glasslike carbon using substantia nigra dopaminergic cells derived from transgenic mouse embryos. PLoS One. 2017;12(3):e0173978.

80. Fernandes AR, Chari DM. Part II: functional delivery of a neurotherapeutic gene to neural stem cells using minicircle DNA and nanoparticles: translational advantages for regenerative neurology. J Control Release. 2016;238:300-310.

81. Genchi GG, Ceseracciu L, Marino A, et al. P(VDF-TrFE)/BaTiO3 nanoparticle composite films mediate piezoelectric stimulation and promote differentiation of SH-SY5Y neuroblastoma cells. Adv Healthc Mater. 2016;5(14):1808-1820.

82. Schulte C, Ripamonti M, Maffioli E, et al. Scale invariant disordered nanotopography promotes hippocampal neuron development and maturation with involvement of mechanotransductive pathways. Front Cell Neurosci. 2016;10:267.

83. Santos T, Ferreira R, Quartin E, et al. Blue light potentiates neurogenesis induced by retinoic acid-loaded responsive nanoparticles. Acta Biomater. 2017;59:293-302.

84. Zhao Y, Jiang Y, Lv W, et al. Dual targeted nanocarrier for brain ischemic stroke treatment. J Control Release. 2016;233:64-71.

85. Sun Y, Li W, Wu X, et al. Functional self-assembling peptide nanofiber hydrogels designed for nerve degeneration. ACS Appl Mater Interfaces. 2016;8(3):2348-2359.

86. Kim E, Yoo SJ, Kim E, et al. Nano-patterned SU-8 surface using nanosphere-lithography for enhanced neuronal cell growth. Nanotechnology. 2016;27(17):175303.

87. Song L, Wang K, Li Y, Yang Y. Nanotopography promoted neuronal differentiation of human induced pluripotent stem cells. Colloids Surf B Biointerfaces. 2016;148:49-58.

88. Saraiva SM, Castro-López V, Pañeda C, Alonso MJ. Synthetic nanocarriers for the delivery of polynucleotides to the eye. Eur J Pharm Sci. 2017;103:5-18.

89. Mdzinarishvili A, Sutariya V, Talasila PK, Geldenhuys WJ, Sadana P. Engineering triiodothyronine (T3) nanoparticle for use in ischemic brain stroke. Drug Deliv Transl Res. 2013;3(4):309-317.

90. Ferreira R, Fonseca MC, Santos T, et al. Retinoic acid-loaded polymeric nanoparticles enhance vascular regulation of neural stem cell survival and differentiation after ischaemia. Nanoscale. 2016;8(15): 8126-8137.
91. Gliga AR, Edoff K, Caputo F, et al. Cerium oxide nanoparticles inhibit differentiation of neural stem cells. Sci Rep. 2017;7(1):9284

92. Arya A, Gangwar A, Singh SK, et al. Cerium oxide nanoparticles promote neurogenesis and abrogate hypoxia-induced memory impairment through AMPK-PKC-CBP signaling cascade. Int J Nanomedicine. 2016;11:1159-1173

93. Ducray AD, Stojiljkovic A, Möller A, et al. Uptake of silica nanoparticles in the brain and effects on neuronal differentiation using different in vitro models. Nanomedicine. 2017;13(3):1195-1204.

94. Zhang R, Li Y, Hu B, Lu Z, Zhang J, Zhang X. Traceable nanoparticle delivery of small interfering RNA and retinoic acid with temporally release ability to control neural stem cell differentiation for Alzheimer's disease therapy. Adv Mater. 2016;28(30):6345-6352.

95. Ducray AD, Felser A, Zielinski J, et al. Effects of silica nanoparticle exposure on mitochondrial function during neuronal differentiation. J Nanobiotechnology. 2017;15(1):49.

96. Guo J, Filpponen I, Johansson LS, et al. Complexes of magnetic nanoparticles with cellulose nanocrystals as regenerable, highly efficient, and selective platform for protein separation. Biomacromolecules 2017;18:898-905.

97. Pampaloni NP, Scaini D, Perissinotto F, Bosi S, Prato M, Ballerini L. Sculpting neurotransmission during synaptic development by 2D nanostructured interfaces. Nanomedicine. Epub 2017 May 25.

98. Hu F, Zhang X, Liu H, et al. Neuronally differentiated adipose-derived stem cells and aligned PHBV nanofiber nerve scaffolds promote sciatic nerve regeneration. Biochem Biophys Res Commun. 2017;489(2):171-178.

99. Orlando A, Cazzaniga E, Tringali M, et al. Mesoporous silica nanoparticles trigger mitophagy in endothelial cells and perturb neuronal network activity in a size- and time-dependent manner. Int J Nanomedicine. 2017;12:3547-3559.

100. Toma M, Belu A, Mayer D, Offenhäusser A. Flexible gold nanocone array surfaces as a tool for regulating neuronal behavior. Small. 2017;13(24):1-11.

101. Chung CY, Lin MH, Lee IN, Lee TH, Lee MH, Yang JT. Brain-derived neurotrophic factor loaded PS80 PBCA nanocarrier for in vitro neural differentiation of mouse induced pluripotent stem cells. Int J Mol Sci. 2017;18(3):E663.

102. Marcianes P, Negro S, García-García L, Montejo C, Barcia E, Fernández-Carballido A. Surface-modified gatifloxacin nanoparticles with potential for treating central nervous system tuberculosis. Int $J$ Nanomedicine. 2017;12:1959-1968.

103. Espadas-Alvarez AJ, Bannon MJ, Orozco-Barrios CE, et al. Regulation of human GDNF gene expression in nigral dopaminergic neurons using a new doxycycline-regulated NTS-polyplex nanoparticle system. Nanomedicine. 2017;13(4):1363-1375.

104. Lee SJ, Zhu W, Heyburn L, Nowicki M, Harris B, Zhang LG. Development of novel 3-D printed scaffolds with core-shell nanoparticles for nerve regeneration. IEEE Trans Biomed Eng. 2017;64(2):408-418.

105. Kuo YC, Rajesh R. Nerve growth factor-loaded heparinized cationic solid lipid nanoparticles for regulating membrane charge of induced pluripotent stem cells during differentiation. Mater Sci Eng C Mater Biol Appl. 2017;77:680-689.

106. Niu S, Zhang LK, Zhang L, et al. Inhibition by multifunctional magnetic nanoparticles loaded with alpha-synuclein RNAi plasmid in a Parkinson's disease model. Theranostics. 2017;7(2):344-356.

107. Aydemir Sezer U, Ozturk K, Aru B, YanıkkayaDemirel G, Sezer S, Bozkurt MR. Zero valent zinc nanoparticles promote neuroglial cell proliferation: a biodegradable and conductive filler candidate for nerve regeneration. J Mater Sci Mater Med. 2017;28(1):19.

108. Defteralı Ç, Verdejo R, Majeed S, et al. In vitro evaluation of biocompatibility of uncoated thermally reduced graphene and carbon nanotube-loaded PVDF membranes with adult neural stem cell-derived neurons and glia. Front Bioeng Biotechnol. 2016;4:94.

109. Kandalam S, Sindji L, Delcroix GJ, et al. Pharmacologically active microcarriers delivering BDNF within a hydrogel: novel strategy for human bone marrow-derived stem cells neural/neuronal differentiation guidance and therapeutic secretome enhancement. Acta Biomater. 2017;49:167-180. 
110. Suarato G, Lee SI, Li W, et al. Micellar nanocomplexes for biomagnetic delivery of intracellular proteins to dictate axon formation during neuronal development. Biomaterials. 2017;112:176-191.

111. Zennaro C, Rastaldi MP, Bakeine GJ, et al. Nanoporous surface is essential for glomerular podocyte differentiation in three-dimensional culture. Int J Nanomedicine. 2016;11:4957-4973.

112. Papadimitriou SA, Robin MP, Ceric D, O’Reilly RK, Marino S, Resmini M. Fluorescent polymeric nanovehicles for neural stem cell modulation. Nanoscale. 2016;8(39):17340-17349.

113. Xiao S, Zhou D, Luan P, et al. Graphene quantum dots conjugated neuroprotective peptide improve learning and memory capability. Biomaterials. 2016;106:98-110.

114. Huang K, Delport G, Orcin-Chaix L, Drummond C, Lauret JS, Penicaud A. Single layer nano graphene platelets derived from graphite nanofibres. Nanoscale. 2016;8(16):8810-8818.

115. Gällentoft L, Pettersson LM, Danielsen N, Schouenborg J, Prinz CN, Linsmeier CE. Impact of degradable nanowires on long-term brain tissue responses. J Nanobiotechnology. 2016;14(1):64.

116. Hsiao IL, Hsieh YK, Chuang CY, Wang CF, Huang YJ. Effects of silver nanoparticles on the interactions of neuron- and glia-like cells: toxicity, uptake mechanisms, and lysosomal tracking. Environ Toxicol. 2017;32(6):1742-1753.

117. Shi X, Xiao Y, Xiao H, Harris G, Wang T, Che J. Topographic guidance based on microgrooved electroactive composite films for neural interface. Colloids Surf B Biointerfaces. 2016;145:768-776.

118. Vedagiri A, Thangarajan S. Mitigating effect of chrysin loaded solid lipid nanoparticles against Amyloid $\beta 25-35$ induced oxidative stress in rat hippocampal region: an efficient formulation approach for Alzheimer's disease. Neuropeptides. 2016;58:111-125.

119. Tavakol S, Mousavi SMM, Tavakol B, Hoveizi E, Ai J, Sorkhabadi SMR. Mechano-transduction signals derived from self-assembling peptide nanofibers containing long motif of laminin influence neurogenesis in in-vitro and in-vivo. Mol Neurobiol. 2017;54(4):2483-2496.

120. Hanafy AS, Farid RM, Helmy MW, ElGamal SS. Pharmacological, toxicological and neuronal localization assessment of galantamine/ chitosan complex nanoparticles in rats: future potential contribution in Alzheimer's disease management. Drug Deliv. 2016;23(8): 3111-3122.
121. Hesari Z, Soleimani M, Atyabi F, et al. A hybrid microfluidic system for regulation of neural differentiation in induced pluripotent stem cells. J Biomed Mater Res A. 2016;104(6):1534-1543.

122. Yadav S, Gandham SK, Panicucci R, Amiji MM. Intranasal brain delivery of cationic nanoemulsion-encapsulated TNF $\alpha$ siRNA in prevention of experimental neuroinflammation. Nanomedicine. 2016; 12(4):987-1002.

123. Li P, Xu T, Wu S, Lei L, He D. Chronic exposure to graphene-based nanomaterials induces behavioral deficits and neural damage in Caenorhabditis elegans. J Appl Toxicol. 2017;37(10):1140-1150.

124. Sulejczak D, Taraszewska A, Chrapusta SJ, Dziewulska D, Nakielski P, Rafałowska J. Nanofiber mat spinal cord dressing-released glutamate impairs blood-spinal cord barrier. Folia Neuropathol. 2016;54(4): 392-404.

125. Marei HE, Elnegiry AA, Zaghloul A, et al. Nanotubes impregnated human olfactory bulb neural stem cells promote neuronal differentiation in Trimethyltin-induced neurodegeneration rat model. $J$ Cell Physiol. 2017;232(12):3586-3597.

126. Mashock MJ, Zanon T, Kappell AD, Petrella LN, Andersen EC, Hristova KR. Copper oxide nanoparticles impact several toxicological endpoints and cause neurodegeneration in Caenorhabditis elegans. PLoS One. 2016;11(12):e0167613.

127. Coccini T, Caloni F, Ramírez Cando LJ, De Simone U. Cytotoxicity and proliferative capacity impairment induced on human brain cell cultures after short- and long-term exposure to magnetite nanoparticles. J Appl Toxicol. 2017;37(3):361-373.

128. Wu T, He K, Ang S, et al. Impairments of spatial learning and memory following intrahippocampal injection in rats of 3-mercaptopropionic acid-modified CdTe quantum dots and molecular mechanisms. Int J Nanomedicine. 2016;11:2737-2755.

129. Latronico T, Depalo N, Valente G, et al. Cytotoxicity study on luminescent nanocrystals containing phospholipid micelles in primary cultures of rat astrocytes. PLoS One. 2016;11(4):e0153451.

130. Jeon YM, Lee MY, Airborne nanoparticles induce autophagic cell death of human neuronal cells. J Appl Toxicol. 2016;36(10):1332-1342.
International Journal of Nanomedicine

\section{Publish your work in this journal}

The International Journal of Nanomedicine is an international, peerreviewed journal focusing on the application of nanotechnology in diagnostics, therapeutics, and drug delivery systems throughout the biomedical field. This journal is indexed on PubMed Central, MedLine, CAS, SciSearch ${ }^{\circledR}$, Current Contents ${ }^{\circledR} /$ Clinical Medicine,

\section{Dovepress}

Journal Citation Reports/Science Edition, EMBase, Scopus and the Elsevier Bibliographic databases. The manuscript management system is completely online and includes a very quick and fair peer-review system, which is all easy to use. Visit http://www.dovepress.com/ testimonials.php to read real quotes from published authors. 